\title{
Outcome from acute respiratory distress syndrome: Is it really improving?
}

\author{
JESÚS VILLAR MD PhD FCCM, ARTHUR S SLUTSKY MD \\ Research Institute, Hospital de la Candelaria, Tenerife, Canary Islands, Spain; \\ and Samuel Lunenfeld Research Institute, Mount Sinai Hospital, University of Toronto, \\ Toronto, Ontario
}

J VILLAR, AS SLUTSKY. Outcome from acute respiratory distress syndrome: Is it really improving? Can Respir J 1996;3(6):417-421.

Assessing the severity of the acute respiratory distress syndrome (ARDS) is important in determining the prognosis in any given patient and in assessing the adequacy of various forms of therapy. Mortality from ARDS has been high since the syndrome was first described almost 30 years ago. Sepsis and extrapulmonary organ failure are the major contributing factors affecting the probability of survival in patients with ARDS. Although studies of ARDS frequently are not comparable because of varying definitions and inhomogeneity of patients, it appears that the mortality rate from ARDS has dropped by about $20 \%$ in the past 10 years.

Key Words: Acute respiratory distress syndrome
Pronostic du syndrome de détresse respiratoire aiguë : Y-a-t-il réellement une amélioration?

RÉSUMÉ : L'évaluation de la gravité du syndrome de détresse respiratoire aiguë (SDRA) est importante pour établir le pronostic chez tout patient donné et pour évaluer la pertinence de différents modes de traitement. Presque 30 années après la première description de ce syndrome, la mortalité qui y est associée reste élevée. Le choc septique et la défaillance d'organes extrapulmonaires sont les facteurs principaux qui affectent la probabilité de la survie chez les patients atteints du SDRA. Bien que les études sur le SDRA ne puissent être comparées par manque d'une définition bien établie et à cause de l'hétérogénéité des patients, il semble que le taux de mortalité associé au SDRA ait chuté d'environ $20 \%$ dans la dernière décennie.
$\mathrm{I}^{\mathrm{n}}$ 1967, Ashbaugh et al (1) defined the acute respiratory distress syndrome (ARDS) in 12 adult patients. The patients were identified as having respiratory distress with tachypnea, hypoxemia, decreased respiratory system compliance and bilateral pulmonary infiltrates. The survival rate was $42 \%$, and on pathology the nonsurvivors had heavy lungs, atelectasis, interstitial and alveolar edema, as well as hyaline membranes. Since that time, the hallmarks of this syndrome have included a risk factor for the development of ARDS; severe hypoxemia with a relatively high fraction of inspired oxygen $\left(\mathrm{FiO}_{2}\right)$; decreased pulmonary compliance; and bilateral pulmonary infiltrates, in a setting in which cardiogenic pulmonary edema has been ruled out. Sepsis is the most common predisposing factor for the development of ARDS, accounting for approximately $35 \%$ to $50 \%$ of the mortality of ARDS. However, the major determinant of out-

Correspondence: Dr Jesús Villar, Director, Research Institute, Hospital de la Candelaria, Santa Cruz, de Tenerife, Canary Islands, Spain. Telephone 34-22-602389, fax 34-22-600562, e-mail jvillar@arrakis.es 
TABLE 1

Outcome data in acute respiratory distress syndrome from 1967 to 1979

\begin{tabular}{lccc}
\hline Authors (reference) & Years & Patients (n) & Survival (\%) \\
\hline Ashbaugh et al (1) & 1967 & 12 & 42 \\
Shimada et al (10) & $1974-1977$ & 14 & 29 \\
Bartlett et al (11) & $1975-1977$ & 686 & 34 \\
Bell et al (12) & $1978-1980$ & 141 & 26 \\
Pontoppidan et al (14) & $1978-1983$ & 144 & 38 \\
Fein et al (13) & 1979 & 21 & 19 \\
Pepe et al (15) & $1979-1980$ & 46 & 39 \\
Bellamy et al (16) & $1979-1981$ & 39 & 18 \\
\hline
\end{tabular}

come in ARDS is the failure of other vital organ systems. Several studies have established that the greater the number of organ systems failing, the worse the prognosis (2).

\section{EVALUATING THE PROGNOSIS OF ARDS}

Assessing the severity of ARDS is important in determining the prognosis in any given patient and in assessing the adequacy of various forms of therapy. The diagnosis of ARDS is currently based on a combination of clinical, hemodynamic and arterial oxygenation criteria. These criteria allow the inclusion of a heterogeneous group of patients into the diagnosis of ARDS. Its high mortality rate is frequently, at least partly, attributable to the nature of the grave underlying condition. Hence, it seems more appropriate to consider the prognosis not only of the pulmonary lesion but also of the underlying condition. In one study by Suchyta et al (3) in which 215 patients with ARDS were studied, only one patient out of a group of 27 patients with lymphoma, metastatic cancer, hepatic necrosis, acquired immunodeficiency syndrome or bowel infarction survived (mortality $96 \%)$. In contrast, 101 of 188 (54\%) of the remaining patients survived.

Several groups of investigators $(2,4)$ have repeatedly pointed out that sepsis and extrapulmonary organ failure are the major contributing factors affecting the probability of survival in patients with acute respiratory failure. Irreversible respiratory failure is the cause of death in fewer than $20 \%$ of ARDS patients. Reported mortality data are greatly dependent on the specific criteria used for the diagnosis of ARDS. The lack of a universal definition for this syndrome (5) means that many patients with 'simple' acute respiratory failure from other causes are still commonly diagnosed as having ARDS.

A number of investigators have identified various factors that indicate a poor prognosis in patients with ARDS. In the European Cooperative Study for ARDS (6), which enrolled about 600 patients, mortality ranged from $48 \%$ in patients under 30 years old, to $82 \%$ in patients between 70 and 90 years of age. Similarly, the risk factor associated with the development of ARDS is an important factor. In the European Study, the survival rate was about $65 \%$ in patients with trauma, whereas it was less than $20 \%$ in patients with pneumonia. Since ARDS is characterized by severe hypoxemia and other related physiological problems, several authors have examined whether various parameters of oxygenation or lung mechanics would be useful in evaluating prognosis. Villar et al $(7,8)$ studied lung mechanics, oxygenation defect and the hemodynamic profile in 225 patients with acute respiratory failure. In the non-ARDS patients, they found that values of alveolar-atrial oxygen diffusion greater than 300 $\mathrm{mmHg}$, compliance less than $27 \mathrm{~cm} \mathrm{H}_{2} \mathrm{O}$, peak inspiratory pressure (PIP) greater than $35 \mathrm{~cm} \mathrm{H} \mathrm{H}_{2} \mathrm{O}$, and the application of an $\mathrm{FiO}_{2}$ of at least 0.5 or minute ventilation greater than $12 \mathrm{~L}$ indicated a poor prognosis. However, none of the parameters of pulmonary function analyzed in patients with ARDS predicted a lower or higher mortality rate. Only the lower mean age of the survivors was significantly different (33 versus 51 years). This lack of correlation with mortality and the observation that mortality is correlated more with the underlying disease and development of multiple organ failure reinforces the concept that ARDS should be considered to be a systemic disease and not just a disease of the lungs. These parameters may just be markers for the disease and not in themselves predictive. Fowler et al (9) studied a cohort of 88 patients with ARDS and found three descriptors at the onset of the syndrome that correlated with a poor outcome: fewer than 10 band forms on peripheral blood smear; persistent arterial $\mathrm{pH}$ less than 7.40; and initial serum bicarbonate less than $20 \mathrm{mmol} / \mathrm{L}$. These findings seemed to indicate early organ dysfunction. The mortality rate in patients presenting with all three of these abnormalities was greater than $80 \%$, whereas the mortality rate without these abnormalities was $40 \%$.

\section{ARDS OUTCOME FROM 1967 TO 1995: A COMPREHENSIVE REVIEW}

Mortality rates of ARDS have been high since the syndrome was first described. While our knowledge about pathophysiological aspects of ARDS has increased, improvements in supportive care allegedly have not led to an increase in the survival rates. Differences in patient selection, in predisposition for ARDS, in patient age and in severity of underlying disease may explain the differences in mortality rates reported in most series.

1967-1979 outcome data: In their original paper, Ashbaugh et al (1) reported a survival rate of $42 \%$ in their series of 12 patients. Subsequent reports during the 1970 s by different groups of investigators have reported survival rates ranging from $19 \%$ to $34 \%$ (Table 1). Shimada et al (10) from Japan reported a mortality rate of $71 \%$ in 14 postoperative patients who developed ARDS. Most patients from that series had cancer and developed sepsis before or during intensive care unit (ICU) admission. Bartlett et al (11) carried out a collaborative National Institutes of Health study from 1975 to 1977 involving nine centres and 686 adult patients with acute respiratory failure. The overall mortality rate was $66 \%$ and there was no physiological or treatment variable that could be used to discriminate the survivors from the nonsurvivors. However, mortality did increase with increasing number of failing organ systems for both patients presenting with iso- 
TABLE 2

Outcome data in acute respiratory distress syndrome from 1980 to 1989

\begin{tabular}{lccc}
\hline Authors (reference) & Years & Patients (n) & Survival (\%) \\
\hline Fowler et al (17) & $1980-1981$ & 88 & 35 \\
Mancebo et al (18) & $1981-1983$ & 35 & 31 \\
Montgomery et al (4) & $1981-1982$ & 47 & 32 \\
Hudson et al (19) & $1983-1985$ & 179 & 38 \\
ECS (6) & $1985-1987$ & 583 & 41 \\
Villar and Slutsky (5) & $1983-1985$ & 74 & 50 \\
Webster et al (20) & 1985 & 139 & 62 \\
Suchyta et al (3) & $1987-1990$ & 215 & 47 \\
\hline
\end{tabular}

ECS European Collaborative Study

lated lung failure and those presenting with multiple organ system failure. Similar high mortality rates were reported by Bell et al (12) and Fein et al (13) in ARDS patients treated in the late 1970s. Bell et al (12) found that all patients with bacteremia who had a clinically identified site of infection survived, whereas all patients with bacteremia without a clinically identified site of infection died. Fein et al (13) identified 21 ARDS patients from a population of 116 consecutive patients with sepsis. In their study, shock preceded all cases of ARDS, and age, compromised host status and type of sepsis were not significantly different between the ARDS and non-ARDS groups.

In the early 1980s, Pontoppidan et al (14) from the Massachusetts General Hospital and Pepe et al (15) from the University of Washington reported mortality rates of $62 \%$ and $61 \%$, respectively. In the Massachusetts General Hospital study, 144 patients with ARDS were studied over a fouryear period. For 98 patients with the moderate form of ARDS the mortality rate was $50 \%$, and for 46 patients who met the criteria for the severe form mortality was $89 \%$. Pepe et al (15) identified 46 ARDS patients from 136 consecutive patients with acute respiratory failure over an 18 -month period. Of the ARDS cases, $76 \%$ occurred in the initial $24 \mathrm{~h}$ after the diagnosis of the predisposing clinical condition. Bellamy and Oye (16) reviewed the hospital outcome and underlying diagnoses in 39 patients with ARDS admitted to the ICU over a two-year period. Only seven patients survived hospitalization. This very high mortality rate (82\%) correlated quite well with the underlying diagnoses: 27 patients had hematological/oncological diseases, and only one of them survived. Six patients survived from the group of 12 patients with other clinical conditions such as pneumonia, endocarditis or sepsis. 1980-1989 outcome data: In the early 1980s, most ARDS studies reported survival rates between $31 \%$ and $36 \%$ (Table 2). Fowler at al (17) identified 88 ARDS patients in a oneyear survey of patients admitted to three hospitals in Denver. The mortality rate was $65 \%$, and $90 \%$ of patients died within 14 days of onset of the syndrome. There were no age- or sex-specific differences in either incidence or mortality rates. Aspiration pneumonia and sepsis were the predisposing factors associated with the highest mortality rates. Mancebo and Artigas (18) in Spain retrospectively evaluated 35 patients with ARDS. In that study, the most common cause of ARDS
TABLE 3

Outcome data in acute respiratory distress syndrome from 1990 to 1995

\begin{tabular}{lccc}
\hline Authors (reference) & Years & Patients (n) & Survival (\%) \\
\hline Sloane et al (21) & $1990-1991$ & 153 & 46 \\
Lewandowski & 1991 & 17 & 41 \\
$\quad$ et al (22) & & & \\
Vasilyev et al (23) & $1991-1992$ & 309 & 28 \\
Lee et al (24) & $1990-1993$ & 41 & 34 \\
Morris et al (25) & $1988-1992$ & 19 & 42 \\
Meduri et al (26) & $1992-1993$ & 27 & 48 \\
\hline
\end{tabular}

was pneumonia and the overall mortality rate was $69 \%$. Older age, greater number of failing organs and the presence of systemic infection were associated with a poor outcome. A similar mortality rate (68\%) was reported in 1985 by Montgomery et al (4) in a prospective study. They identified 47 patients with ARDS over a 30-month period. Only 16\% of deaths were from irreversible respiratory failure. Most early deaths were attributed to the underlying illness or injury, whereas the majority of late deaths were related to sepsis. In a recent publication, Hudson et al (19) reported their experience on 179 ARDS patients from data collected in the 1980s. The overall mortality rate was $62 \%$.

Since 1985, almost all published studies have reported a survival rate higher than $40 \%$. The first of these studies was the European Collaborative Study (6). This study included almost 600 ARDS patients and demonstrated that two criteria, severe hypoxemia and pulmonary artery occlusion pressure, had introduced a selection bias into previous published clinical reports, selecting a small group of patients with an unusually poor prognosis. The reported mortality rate was $59 \%$, and the prognosis was determined by etiology, preexisting disease, age and other organ failure.

Villar and Slutsky (5) were the first to study the incidence of ARDS retrospectively, reporting an increased survival rate among ARDS patients and showing a mortality rate much lower than previously reported from other centres. During a three-year period, 74 ARDS patients were identified among 1997 critically ill patients admitted into the ICU. The mortality rate was $50 \%$. Similar to most other series, the most common predisposing factor for the development of ARDS was sepsis. The coexistence of sepsis and extrapulmonary organ failure was the major contributing factor for the high mortality (2). Similarly, Webster et al (20) reported a mortality rate of $38 \%$ based on a retrospective survey of 139 patients without standard criteria for the diagnosis of ARDS. In 1992, Suchyta et al (3) reported a mortality rate of $53 \%$ in a series of 215 patients with ARDS prospectively screened from 1987 to 1990 . They found that age younger than 65 years and aspiration pneumonia as a predisposing factor were associated with a better survival. Forty per cent of their nonsurvivors died of respiratory failure, a finding that is in contrast to most previous reports $(2,4,6)$.

1990-1995 outcome data: Sloane et al (21) organized a 


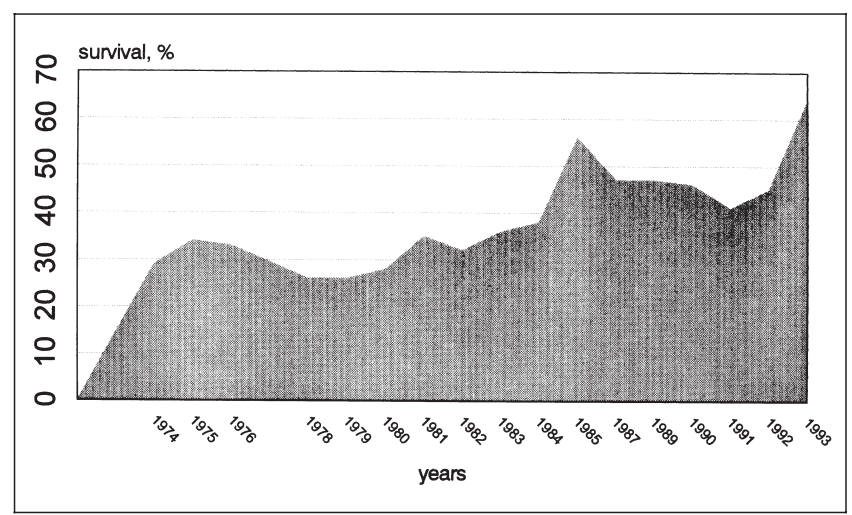

Figure 1) Acute respiratory distress syndrome survival from 1974 to 1993

multicentre registry over a two-year period and enrolled 153 patients with ARDS to study the clinical course of the syndrome. The mortality rate was $54 \%$ (Table 3), and it was significantly greater in older patients $(75 \%$ in patients more than 60 years old versus $37 \%$ in the younger patients). Sepsis was the most common risk factor, and the mortality in the septic patients was higher than that in the trauma patients (64\% versus $42 \%$ ). Lewandowski et al (22) carried out a multicentre study in 72 ICUs from Berlin to determine the incidence and mortality of acute respiratory failure. During the two-month study period they identified 17 ARDS patients among 508 patients with acute respiratory failure. This figure represents an incidence of three cases/100,000 population, an incidence within the range of those previously reported by Villar and Slutsky (5) and Webster et al (20). The mortality rate in the ARDS group was 59\%.

Vasilyev and colleagues (23) conducted an international multicentre prospective survey to determine the hospital survival rates of patients with acute respiratory failure who were managed in modern ICUs, using 1990s support and treatment techniques. Twenty-five centres participated in the survey: 11 from United States and 14 from Europe. A total of 1426 patients were surveyed during a 60-day study period. All patients received an $\mathrm{FiO}_{2}$ greater than 0.5 for more than $24 \mathrm{~h}$. The patients were prospectively divided into two groups: one group of 375 patients comprised those who were either hypoxemic or hypercarbic; and the other group of 1051 patients comprised those who were neither hypoxemic nor hypercarbic under the same conditions $\left(\mathrm{PaO}_{2}\right.$ less than $60 \mathrm{mmHg}$ with $\mathrm{FiO}_{2}$ greater than $0.5 ; \mathrm{PaCO}_{2}$ greater than 40 at a flow rate greater than $15 \mathrm{~L} / \mathrm{min}$ ). Only 309 patients were identified as having ARDS and their mortality was $72 \%$, twice the mortality rate of the nonhypoxemic/hypercarbic group (36\%). PIP greater than $50 \mathrm{~cm} \mathrm{H}_{2} \mathrm{O}$ at entry into the survey was associated with a survival rate of less than $20 \%$, whereas PIP less than $30 \mathrm{~cm} \mathrm{H}_{2} \mathrm{O}$ was associated with a survival rate of $60 \%$.

Similar fatality rates were found by Lee et al (24) in England. They retrospectively surveyed 41 patients with ARDS. Mortality rate was also high (66\%), and only the presence of sepsis predicted death. Mortality data by Vasilyev et al (23) and Lee et al (24) are not in agreement with more recent publications. Morris and colleagues (25) performed a randomized clinical trial of pressure-controlled inverse ratio ventilation and extracorporeal carbon dioxide removal for ARDS. They randomized 40 patients. Mortality rate in the 19 mechanical ventilation patients was $58 \%$, much greater than that expected from historical data. Meduri et al (26) studied 27 patients with ARDS to test the hypothesis that unfavourable outcome is related to the presence of a persistent inflammatory response. The overall mortality was $52 \%$.

Differences in patient selection, in severity of underlying disease, in patient age, in predisposition for ARDS, or therapeutic or clinical environment changes may explain the differences in mortality rates reported in various patient series. However, studies of ARDS are frequently not comparable because of varying definitions and the inhomogeneity of patients. To overcome this problem, Milberg et al (27) from Seattle analyzed temporal trends in ARDS fatality rates from 1983 to 1993 at the same institution. Using the same ARDS definition for all patients, they identified 918 patients over the 10-year study period. Overall fatality rates showed no trend from 1983 to 1987, but declined slightly in 1988 and 1989 , and decreased to a low of $36 \%$ in 1993. Similar to most series, patients younger than 60 years old had the higher survival rate. In septic patients, ARDS mortality rates declined steadily, from $67 \%$ in 1990 to $40 \%$ in 1993 . Whether or not the better ARDS survival is due to improved management of the underlying disease, these investigators suggested that institution-specific rates and temporal trends in ARDS mortality rates should be considered in clinical trials designed to prevent ARDS and the high mortality associated with the syndrome.

In summary, although absolute numbers of ARDS patients in most published reports were small, it appears that the mortality rate from ARDS has dropped about $20 \%$ in the past 10 years (Figure 1). Patients who are younger than 60 years of age, who have trauma as a predisposition, and who do not develop sepsis and subsequent extrapulmonary dysfunction are most likely to survive ARDS.

ACKNOWLEDGEMENTS: Supported by Fondo de Investigacion Sanitaria of Spain and the Medical Research Council of Canada.

\section{REFERENCES}

1. Ashbaugh DG, Bigelow DB, Petty TL, Levine BE. Acute respiratory distress in adults. Lancet 1967;ii:319-23.

2. Villar J, Manzano JJ, Blazquez MA, Quintana J, Lubillo S. Multiple system organ failure in acute respiratory failure. J Crit Care 1991;6:75-80.

3. Suchyta MR, Clemmer TP, Elliot CG, Orme JF, Weaver LK. The adult respiratory distress syndrome: a report of survival and modifying factors. Chest 1992;101:1074-9.

4. Montgomery AB, Stager MA, Carrico CJ, Hudson LD. Causes of mortality in patients with adult respiratory distress syndrome. Am Rev Respir Dis 1985;132:485-9.

5. Villar J, Slutsky AS. The incidence of the adult respiratory distress syndrome. Am Rev Respir Dis 1989;140:814-6.

6. Artigas A, Carlet J, LeGall JR, Chastang C, Blanch L, Fernandez R. Clinical presentation, prognostic factors and outcome of ARDS in the European Collaborative Study (1985-1987): a preliminary report. In: Zapol WM, Lemaire F, eds. Acute Respiratory Failure. New York: Marcel Dekker, 1990:37-60. 
7. Villar J, Blazquez MA, Lubillo S, Quintana J, Manzano JL. Pulmonary hypertension in acute respiratory failure. Crit Care Med 1989; 17:523-6.

8. Villar J, Villalobos J, Bolaños J, Manzano JL. Prognostic value of the pulmonary function in acute respiratory failure. Clin Intensive Care 1990;1:157-61.

9. Fowler AA, Hamman RF, Zerbe GO, Benson KN, Hyers TM. Adult respiratory distress syndrome: prognosis after onset. Am Rev Respir Dis 1985;132:472-8.

10. Shimada Y, Yoshiya I, Tanaka K, Sone S, Sakurai M. Evaluation of the progress and prognosis of adult respiratory distress syndrome. Chest 1979;76:180-6

11. Bartlett RH, Morris AH, Fairley B, Hirsch R, O'Connor N, Pontoppidan $\mathrm{H}$. A prospective study of acute hypoxic respiratory failure. Chest 1986;89:684-9.

12. Bell RC, Coalson JJ, Smith JD, Johanson WG. Multiple organ system failure and infection in adult respiratory distress syndrome. Ann Intern Med 1983;99:293-8.

13. Fein AM, Lippmann M, Holtzman H, Eliraz A, Goldberg AK. The risk factors, incidence, and prognosis of ARDS following septicemia. Chest 1983;83:40-2.

14. Pontoppidan H, Hüttemeier PC, Quinn DA. Etiology, demography, and outcome [of acute respiratory failure]. In: Zapol WM, Lemaire F, eds. Adult Respiratory Distress Syndrome. Lenfant C, ed. Lung Biology in Health and Disease vol 50. New York: Marcel Dekker Inc, 1991:1-21.

15. Pepe PE, Potkin RT, Reus DH, Hudson LD, Carrico CJ. Clinical predictors of the adult respiratory distress syndrome. Am J Surg 1982;144:124-30.

16. Bellamy PE, Oye RK. Adult respiratory distress syndrome: hospital charges and outcome according to underlying disease. Crit Care Med 1984;12:622-5.

17. Fowler AA, Hamman RF, Good JT, et al. Adult respiratory distress syndrome: risk with common predispositions. Ann Intern Med 1983;98:593-7.

18. Mancebo J, Artigas A. A clinical study of the adult respiratory distress syndrome. Crit Care Med 1987;15:243-6.

19. Hudson LD, Milberg JA, Anardi D, Maunder RJ. Clinical risks for development of the acute respiratory distress syndrome. Am J Respir Crit Care Med 1995;151:293-301.

20. Webster NR, Cohen AT, Nunn JF. Adult respiratory distress syndrome - how many cases in the UK? Anaesthesia 1988;43:923-6.

21. Sloane PJ, Gee MH, Gottlieb JE, et al. A multicenter registry of patients with acute respiratory distress syndrome. Am Rev Respir Dis 1992;146:419-26.

22. Lewandowski K, Metz J, Deutschmann C, et al. Incidence, severity, and mortality of acute respiratory failure in Berlin, Germany. Am J Respir Crit Care Med 1995;151:1121-5.

23. Vasilyev S, Schaap RN, Mortensen JD. Hospital survival rates of patients with acute respiratory failure in modern respiratory intensive care units. An international, multicenter, prospective survey. Chest 1995; 107:1083-8.

24. Lee J, Turner JS, Morgan CJ, Keogh BF, Evans TW. Adult respiratory distress syndrome: has there been a change in outcome predictive measures? Thorax 1994;49:596-7.

25. Morris AH, Wallace CJ, Menlove RL, et al. Randomized clinical trial of pressure-controlled inverse ratio ventilation and extracorporeal $\mathrm{CO}_{2}$ removal for adult respiratory distress syndrome. Am J Respir Crit Care Med 1994;149:295-305.

26. Meduri GU, Headley S, Kohler G, et al. Persistent elevation of inflammatory cytokines predicts a poor outcome in ARDS. Chest 1995;107:1062-73.

27. Milberg JA, Davis DR, Steinberg KP, Hudson LD. Improved survival of patients with acute respiratory distress syndrome (ARDS): 1983-1993. JAMA 1995;273:306-9. 


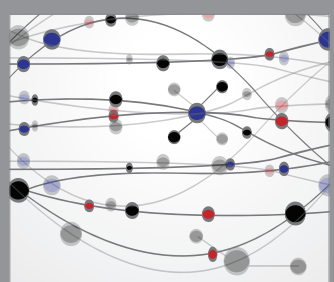

The Scientific World Journal
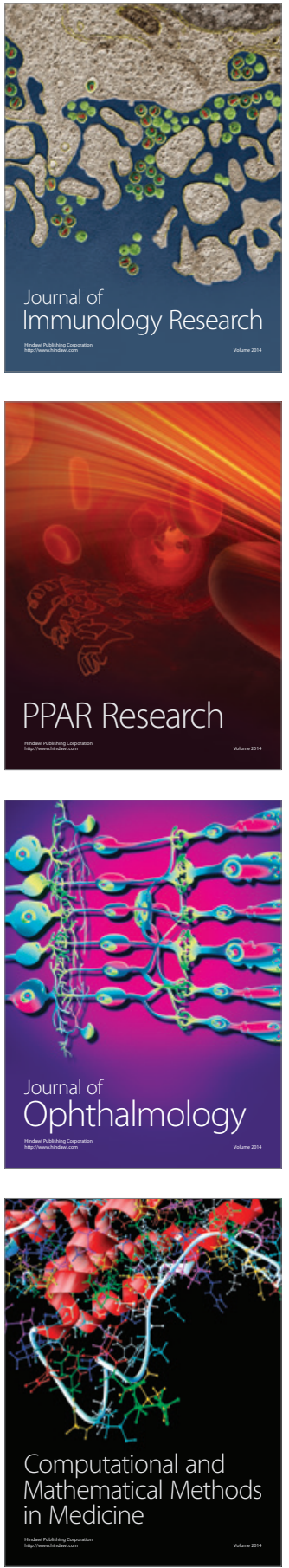

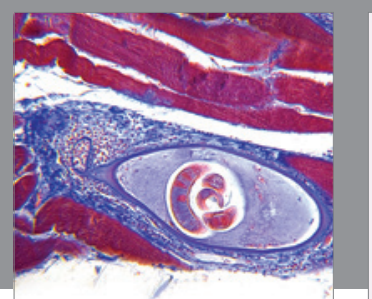

Gastroenterology Research and Practice

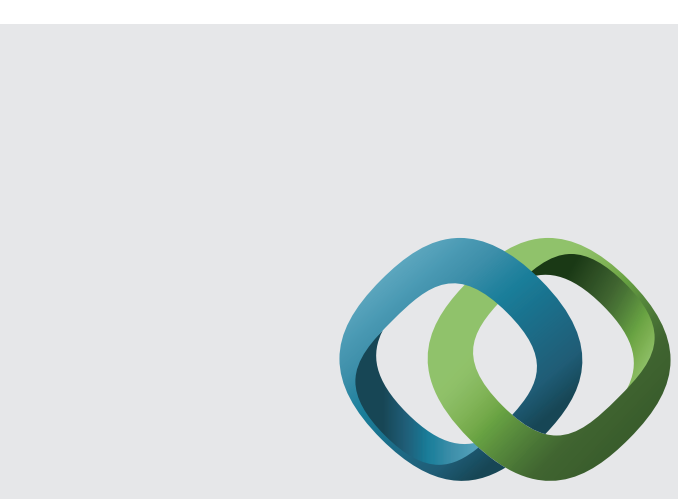

\section{Hindawi}

Submit your manuscripts at

http://www.hindawi.com
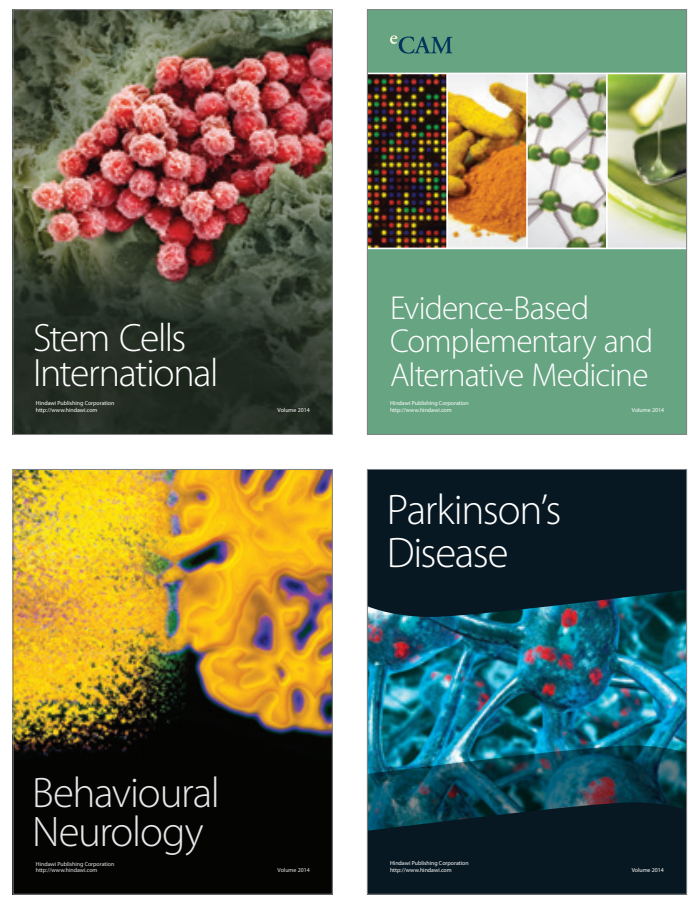
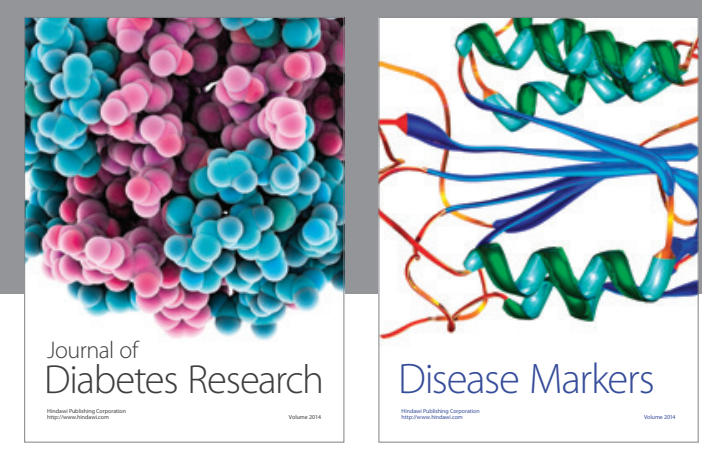

Disease Markers
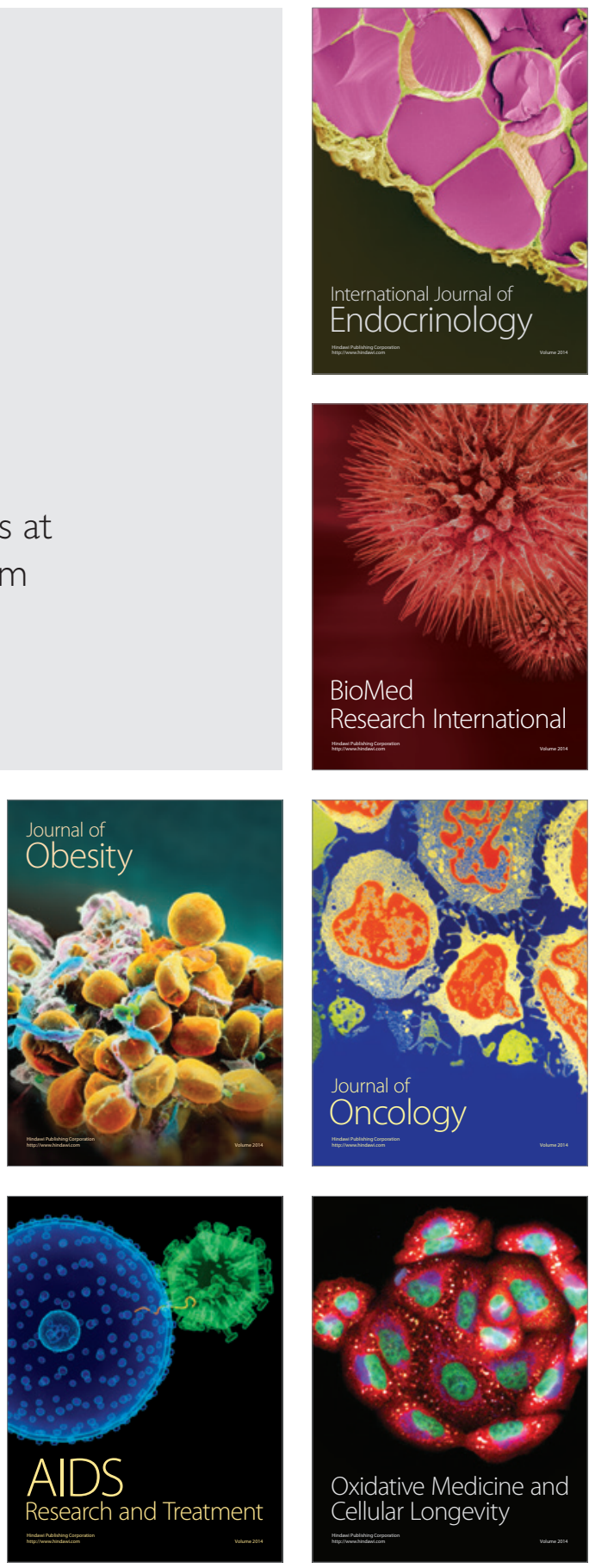